\title{
Homicídios no Rio de Janeiro, Brasil: uma análise da violência letal
}

\author{
Homicides in Rio de Janeiro, Brazil: an analysis of lethal violence
}

\author{
Francisca Letícia Miranda Gadelha Cardoso ${ }^{1}$ \\ Fátima Regina Cecchetto ${ }^{2}$ \\ Juliana Silva Corrêa ${ }^{1}$ \\ Tiago Oliveira de Souza ${ }^{1}$
}

${ }^{1}$ Escola Nacional de Saúde Pública, Fiocruz. Rua Leopoldo Bulhões 1480, Manguinhos. 21041-210 Rio de Janeiro RJ Brasil. gadelhacardoso.leticia@ gmail.com

${ }^{2}$ Instituto Oswaldo Cruz, Fiocruz. Rio de Janeiro RJ Brasil.
Abstract The evolution of rates were analyzed for the following categories: murder, larceny, bodily harm followed by death, homicide for resistance to police resulting in death, policeman killed, missing persons and dead bodies found in the state and city of Rio de Janeiro and in Integrated Public Security Area 16 (AISP 16). An ecological study was conducted for the period from 2002 to 2013, using data from the Public Security Institute. To analyze the time trend and evolution of murder charges, resistance to police resulting in death and missing persons rates, Joinpoint regression was performed, using these rates as the dependent variables and the calendar year as the independent variable. For the other categories only the time trends of the rates were analyzed for the relative change in rates at the beginning and end of the period. There were falls in rates in all categories, except for missing persons. The murder rate showed a significant downward trend in the three locations. The results contributed to definition of the pattern of violence in the three locations based on the dialogue between the social sciences, public health and safety that made it possible to establish subjective and objective aspects linked to the study findings.

Key words Public health, Violence, Homicide, Missing persons, Resistance to police resulting in death
Resumo Analisou-se a evolução de taxas das categorias homicídio doloso, latrocínio, lesão corporal seguida de morte, homicídio por auto de resistência, policial morto, pessoa desaparecida e encontro de cadáver, no Estado e na cidade do Rio de Janeiro e na Área Integrada de Segurança Pública 16 (AISP 16). Para tanto, foi realizado estudo ecológico, no período de 2002 a 2013, utilizando os dados do Instituto de Segurança Pública. Para análise da evolução temporal e tendência das taxas de homicídio doloso, de autos de resistência e de pessoas desaparecidas foi realizada regressão Joinpoint, considerando como variável dependente as referidas taxas e como variável independente $o$ ano calendário. Para as demais categorias analisou-se apenas a evolução temporal das taxas a partir do cálculo da variação relativa destas no início e no final do período. Houve queda de taxas em todas as categorias, com exceção de pessoas desaparecidas. A taxa de homicídio doloso apresentou tendência significativa de decréscimo nas três localidades. Os resultados contribuíram para descrever o padrão da violência nas três localidades a partir do diálogo entre as ciências sociais, saúde e segurança pública, o que permitiu contemplar aspectos subjetivos e objetivos ligados aos achados do estudo.

Palavras-chave Saúde pública, Violência, Homicídio, Pessoas desaparecidas, Auto de resistência 


\section{Introdução}

Os homicídios no Brasil representam uma questão nacional de saúde pública, sendo a principal causa de morte de jovens entre 15 e 24 anos, moradores das periferias e áreas metropolitanas dos centros urbanos. Estudos evidenciam o quanto a violência tem se destacado como um fator que conduz parte significativa de jovens à morte precoce, impedindo-os de alcançar a maturidade e de usufruir do desenvolvimento socioeconômico alcançado pelo país na última década. Mais da metade dos mortos por homicídios em 2011 no Brasil eram de jovens, em sua maioria homens e negros ${ }^{1}$. Por esse motivo, o homicídio juvenil como problema social de grande envergadura requer o entendimento da interação perversa entre fatores estruturais relativos às causas socioeconômicas e aos processos culturais dinâmicos, originados, por exemplo, de representações rígidas sobre identidades de gênero e de estereótipos de "raça"/cor.

Nesse quadro, importantes estudos conjugando métodos mistos têm apontado a incidência, no Rio de Janeiro, de uma das maiores taxas de homicídio de jovens e negros entre as capitais ${ }^{2-4}$. Boa parte desses trabalhos se faz acompanhar de análises sobre a violência letal em áreas conflagradas pela presença do "crime-negócio" organizado transnacionalmente ${ }^{4}$. Os estudos reiteram a força com que os intermináveis confrontos violentos pelo controle de mercados ilegais de drogas e armas afetaram de modo desigual os grupos, vitimando principalmente moradores de localidades pobres. Nesse cenário, destacam também a intensificação de uma lógica guerreira vinculada à criminalidade violenta na qual a demonstração do poder de exterminar o inimigo se faz presente nas rivalidades entre integrantes das facções criminosas, de grupos paramilitares (as chamadas "milícias") e das organizações policiais.

Nos últimos anos, entretanto, esse cenário vem se modificando, com a diminuição das taxas de mortalidade por homicídio no estado, ainda que persistam índices de letalidade considerados epidêmicos. Existe uma percepção sobre mudanças na ação de grupos criminosos e de governo ${ }^{5}$ em determinados territórios no estado. Porém, estas precisam ser pensadas também a partir de alterações nos padrões de violência no país, relacionados, por exemplo, ao processo de interiorização da violência, bem como políticas de enfrentamento da criminalidade violenta em algumas capitais, como é o caso do Sistema Integrado de Metas implantado no Rio de Janeiro desde 2009 e as Unidades de Polícia Pacificadora (UPP) a partir de 2008.

No caso da cidade do Rio, existem controvérsias a respeito da relação causal feita entre algumas intervenções governamentais recentes como as UPP, por exemplo, e a diminuição de homicídios na cidade. Nessa linha, o aumento do número de pessoas desaparecidas também tem suscitado debate, na medida em que não há consenso se o número destas estaria englobando também casos de homicídios, necessitando, portanto, de mais pesquisas sobre o assunto, que não é a proposta deste trabalho.

Assim sendo, é importante que sejam realizados mais estudos ao nível local que contribuam para a elucidação deste panorama, ainda pouco explorado, é o que se pretende realizar aqui a partir da análise em uma Área Integrada de Segurança Pública (AISP).

Sabe-se que são poucos os estudos que trabalham dados de homicídio que não usam, como base de dados, o Sistema de Informação de Mortalidade do Ministério da Saúde (SIM/MS). Desse modo, optou-se por trabalhar com dados do Instituto de Segurança Pública (ISP), reconhecendo a importância de lançar luz sobre as repercussões de políticas de segurança pública na diminuição das taxas de vitimização que afetam a saúde da população.

O objetivo é descrever a evolução das taxas de homicídio doloso, latrocínio, lesão corporal seguida de morte, auto de resistência, policiais mortos em serviço, pessoas desaparecidas e encontro de cadáveres, notificadas pela Secretaria de Segurança Pública, no estado, no município e na AISP 16, no período de 2002 a 2013. Para tanto, lançamos mão de uma perspectiva socioantropológica na sua interface com a saúde coletiva, com intuito de enriquecer o debate sobre violência e saúde pública.

\section{Métodos}

Trata-se de um estudo ecológico do tipo exploratório, de séries temporais, no qual se analisou a evolução temporal e a tendência das taxas das diversas categorias em estudo nas três localidades: estado, município e AISP 16 do Rio de Janeiro, no período de 2002 a 2013. Foram utilizadas as seguintes categorias: Homicídio Doloso, Latrocínio, Lesão Corporal seguida de morte, Auto de Resistência, Policiais Mortos em serviço, Pessoas Desaparecidas e Encontro de Cadáveres. Os dados analisados são disponibilizados pela Secretária de 
Segurança Pública do Estado do Rio de Janeiro, em página eletrônica oficial do estado do ISP, de 2002 a 2013. Após a coleta, os dados foram importados para o ambiente do Rstudio, no qual foram realizados os cálculos, as tabulações e as análises ${ }^{6}$. Cabe aqui apontar que os autos de resistência são caracterizados como homicídios cometidos por policiais em situação de confronto. No setor saúde, a denominação segue a classificação da CID 10, como 'Intervenções legais e operações de guerra'.

A população utilizada no cálculo das taxas para o estado e para a cidade do Rio de Janeiro foi a disponibilizada pelo Instituto Brasileiro de Geografia e Estatística (IBGE), porém, para o ano de 2013 foram utilizadas as populações estimadas, devido a questões de disponibilidade de dados pelo IBGE no período do estudo. Para o cálculo das taxas da AISP 16 foram usadas as populações referidas pelo ISP, por se tratar de uma região estrategicamente selecionada pelo mesmo.

Para análise da evolução temporal e tendência das taxas de homicídio doloso (THD), taxas de autos de resistência (TAR) e taxas de pessoas desaparecidas (TPD) foi realizada regressão Joinpoint, que descreve se em determinados pontos de uma série existem mudanças (aumento ou diminuição) e quantifica as alterações no padrão de evolução das taxas, a um nível de significância de $5 \%$. A variável dependente veio das referidas taxas e a independente, do ano calendário (2002 a 2013). O teste estatístico foi realizado no Jointpoint Regression Program, versão 4.2.0.2, no qual também foram calculadas as variações percentuais anuais (APC), a partir do logaritmo das THD, TAR e TPD. O método Joinpoint utiliza o modelo de regressão linear para identificar pontos de inflexão nas tendências. Nesse modelo, a hipótese nula $\left(\mathrm{H}_{0}\right)$ resulta em um valor da APC igual a zero, quando as taxas não crescem nem diminuem. Valores da APC positivos (maior que zero) ou negativos (menores que zero) indicam incremento e decréscimo de taxas, respectivamente ${ }^{7}$. O teste estatístico foi realizado nas três categorias, THD, TAR e TPD, que apresentaram maior destaque na análise exploratória inicial das taxas de todas aquelas em estudo. Para as demais categorias, foi analisada apenas a evolução temporal das taxas a partir do cálculo da variação relativa (VR\%) delas no início e no final do período.

O ISP é um órgão responsável por pesquisa, análise criminal, capacitação profissional e Coordenação dos Conselhos Comunitários de Segurança no Estado do Rio de Janeiro. A página contém o formato eletrônico do resumo das principais incidências criminais do estado, publicadas mensalmente. O site não disponibiliza informações como idade, sexo e raça.

O contorno geográfico de cada AISP é estabelecido a partir da área de atuação de batalhões da Polícia Militar e as circunscrições das delegacias de Polícia Civil contidas nela, com o objetivo de estabelecer estratégias de trabalho conjunto para redução da criminalidade e integrar as duas instituições às divisões administrativas oficiais ${ }^{8}$.

A AISP 16 é composta por um conjunto de bairros que apresentam IDH (índice de desenvolvimento humano) entre os mais baixos da cidade. Cabe ressaltar que embora sejam definidas oficialmente como bairros, grande parte destas unidades territoriais são representadas socialmente como favelas, em virtude do processo de deteriorização urbana que ocorreu nesses e em outros bairros cariocas, levando ao que se convencionou chamar de favelização, com a crescente percepção da região como um "território da pobreza" . A AISP 16 compreende as unidades territoriais Brás de Pina, Olaria, Penha, Penha Circular, Cordovil, Jardim América, Parada de Lucas, Vigário Geral e Complexo do Alemão, localizados na zona norte da cidade do Rio de Janeiro (Figura 1).

A motivação pela escolha desta região se dá em virtude de complementar pesquisas qualitativas que já vêm sendo desenvolvidas nesta área. Junto a isto, há um interesse particular em observar se há alguma mudança significativa nestes indicadores durante o período analisado, tendo em vista que a AISP 16 engloba grandes Complexos de favelas, como o Complexo da Penha e do Alemão, por exemplo, que por muitos anos foram consideradas áreas críticas na cidade, no que diz respeito aos indicadores de violência.

\section{Resultados}

Houve queda nas taxas de praticamente todas as categorias analisadas no estudo durante o período de doze anos, como pode ser observado através da variação relativa entre o ano inicial e final (Tabela 1). O homicídio doloso apresentou um padrão declinante nas três localidades. Essa categoria registrou as mais elevadas taxas quando comparado às demais no estado e no município do Rio de Janeiro. Na área integrada de segurança pública, o homicídio doloso aparentemente tem uma importância menor que nas outras regiões, com taxas menores sobretudo nos cinco anos iniciais (Tabela 1; Figura 2).

A Figura 3 mostra tendência significativa de decréscimo na taxa de mortalidade por homicí- 

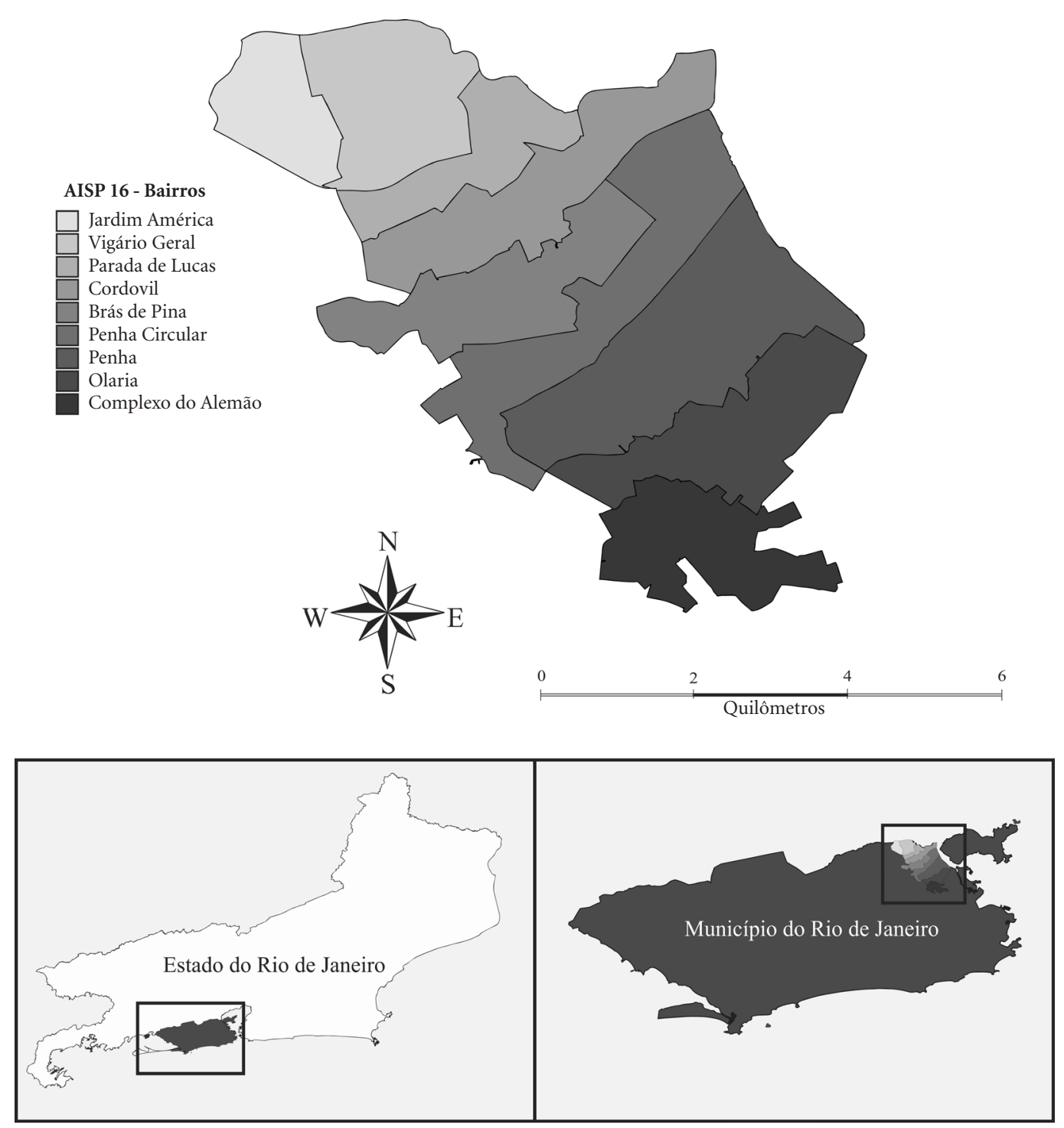

Figura 1. Conjunto de unidades territoriais que compõem a Área Integrada de Segurança Pública 16 (AISP 16). Estado e Município do Rio de Janeiro, 2013.

Fonte: Elaboração própria.

dio doloso, no período de 2005 a 2011 no estado do Rio de Janeiro, com APC = -8, 1 (IC95\%: - 13,8; -2,1); no município a APC de 2009-2013 foi igual a -13,0 (IC95\%: -20,5; -4,7); enquanto que na AISP 16 existe uma incerteza quanto à queda na taxa de homicídio doloso, pois apesar da APC de 2007-2011 = -19,5 sinalizar diminuição, observa-se que valor zero está contido no intervalo (IC95\%: -35,2; 0). Assim, não se pode concluir que existe um real declínio da taxa de homicídio nesse período e nessa localidade. Ainda que apresente taxas de homicídio doloso mais baixas, a AISP 16 mostrou diferentes alterações no padrão de evolução destas, em oposição ao padrão mais semelhante encontrado entre o estado e o município do Rio (Figura 3; Figura 4).

Pessoa desaparecida foi a única categoria avaliada que apresentou incremento da taxa nas três localidades. Na AISP 16, essa categoria apresentou as mais elevadas taxas, em comparação as 
Tabela 1. Número de casos, taxas por 100.000 habitantes e variação relativa (VR\%), segundo categoria, nas três áreas geográficas. Rio de Janeiro (estado, município e AISP 16), 2002 a 2013.

\begin{tabular}{|c|c|c|c|c|c|c|c|c|c|c|c|c|}
\hline \multirow{3}{*}{ Categoria } & \multicolumn{12}{|c|}{ Ano/Região } \\
\hline & \multicolumn{2}{|c|}{2002} & \multicolumn{2}{|c|}{2003} & \multicolumn{2}{|c|}{2004} & \multicolumn{2}{|c|}{2005} & \multicolumn{2}{|c|}{2006} & \multicolumn{2}{|c|}{2007} \\
\hline & $\mathbf{n}$ & $\operatorname{taxa}$ & $\mathbf{n}$ & taxa & $\mathbf{n}$ & $\operatorname{taxa}$ & $\mathbf{n}$ & taxa & $\mathbf{n}$ & $\operatorname{taxa}$ & $\mathbf{n}$ & taxa \\
\hline \multirow{8}{*}{$\begin{array}{l}\text { Homicídio Doloso } \\
\text { Auto de Resistência } \\
\text { Latrocínio } \\
\text { Cadáver Encontrado } \\
\text { Pessoa Desaparecida } \\
\text { Lesão Corporal } \\
\text { Policial Morto }\end{array}$} & \multicolumn{12}{|c|}{ Estado do Rio de Janeiro } \\
\hline & 5202 & 35,3 & 6624 & 44,5 & 6438 & 42,8 & 6620 & 43,0 & 6323 & 40,6 & 6133 & 39,0 \\
\hline & 694 & 4,7 & 1195 & 8,0 & 983 & 6,5 & 1098 & 7,1 & 1063 & 6,8 & 1330 & 8,5 \\
\hline & 152 & 1,0 & 179 & 1,2 & 185 & 1,2 & 210 & 1,4 & 208 & 1,3 & 192 & 1,2 \\
\hline & 1058 & 7,2 & 1625 & 10,9 & 1230 & 8,2 & 911 & 5,9 & 826 & 5,3 & 766 & 4,9 \\
\hline & 3808 & 25,9 & 4800 & 32,3 & 4559 & 30,3 & 4397 & 28,6 & 4562 & 29,3 & 4633 & 29,4 \\
\hline & 51 & 0,3 & 56 & 0,4 & 39 & 0,3 & 59 & 0,4 & 55 & 0,4 & 44 & 0,3 \\
\hline & 29 & 0,2 & 50 & 0,3 & 52 & 0,3 & 33 & 0,2 & 29 & 0,2 & 32 & 0,2 \\
\hline & \multicolumn{12}{|c|}{ Município do Rio de Janeiro } \\
\hline Homicídio Doloso & 1994 & 33,6 & 2574 & 43,1 & 2653 & 44,1 & 2406 & 39,5 & 2465 & 40,2 & 2336 & 37,8 \\
\hline Auto de Resiste & 478 & 8,1 & 798 & 13,4 & 656 & 10,9 & 707 & 11,6 & 673 & 11,0 & 902 & 14,6 \\
\hline Latrocínio & 76 & 1,3 & 98 & 1,6 & 103 & 1,7 & 86 & 1,4 & 117 & 1,9 & 91 & 1,5 \\
\hline Cadáver Encontrado & 569 & 9,6 & 913 & 15,3 & 644 & 10,7 & 430 & 7,1 & 376 & 6,1 & 356 & 5,8 \\
\hline Pessoa Desaparecida & 1596 & 26,9 & 2044 & 34,2 & 1889 & 31,4 & 1732 & 28,4 & 1792 & 29,2 & 1858 & 30,1 \\
\hline $\begin{array}{l}\text { Lesao } \\
\text { Polici. }\end{array}$ & 32 & 0,5 & 25 & 0,4 & 24 & 0,4 & 32 & 0,5 & 31 & 0,5 & 25 & 0,4 \\
\hline Policial Morto & 20 & 0,3 & 40 & 0,7 & 41 & 0,7 & 24 & 0,4 & 25 & 0,4 & 30 & 0,5 \\
\hline & \multicolumn{12}{|c|}{ Área Integrada de Segurança Pública 16} \\
\hline Homicídio Doloso & 121 & 25,9 & 119 & 25,4 & 129 & 28,0 & 149 & 32,1 & 150 & 32,0 & 170 & 36,0 \\
\hline Auto de Resistência & 31 & 6,6 & 108 & 23,0 & 63 & 13,7 & 62 & 13,4 & 63 & 13,5 & 171 & 36,2 \\
\hline & 6 & 1,3 & 3 & 0,6 & 11 & 2,4 & 8 & 1,7 & 18 & 3,8 & 10 & 2,1 \\
\hline Cadáver Encontrado & 50 & 10,7 & 63 & 13,4 & 37 & 8,0 & 34 & 7,3 & 18 & 3,8 & 28 & 5,9 \\
\hline Pessoa Desaparecida & 72 & 15,4 & 118 & 25,2 & 121 & 26,3 & 118 & 25,4 & 125 & 26,7 & 139 & 29,4 \\
\hline Lesão Corporal & 5 & 1,1 & 1 & 0,2 & 2 & 0,4 & - & - & 3 & 0,6 & 2 & 0,4 \\
\hline Policial Morto & 1 & 0,2 & 6 & 1,3 & 3 & 0,7 & 1 & 0,2 & 1 & 0,2 & 7 & 1,5 \\
\hline
\end{tabular}

outras categorias e, com uma variação relativa de $178,4 \%$, mais que dobrou durante o período do estudo (Tabela 1). A Figura 2 mostra que enquanto no estado e no município a distribuição da taxa de pessoa desaparecida é mais simétrica e apresenta pouca variação, na AISP 16 observa-se o contrário, há dispersão de taxas e presença de outlier (Figura 2). Por outro lado, mesmo tendo superado as taxas de homicídio em 2009 no estado e em 2008 no município e na AISP 16, a taxa de pessoa desaparecida não teve tendência de aumento significativa nos pontos (joinpoints) analisados (Figura 4).

Ao analisar o auto de resistência, a AISP 16 merece maior destaque que as demais localidades. As taxas de mortalidade por autos de resistência superaram as de homicídio doloso no ano de 2007, nessa área (Tabela 1). Essa categoria foi a única da AISP 16 a superar o estado e o município em termos de taxas e mediana em toda a série histórica, com grande variabilidade das pri- meiras e uma composição bem assimétrica (Figura 2). Porém, no período de 2007 a 2013, apresentou uma tendência de queda signigicativa, na AISP 16, com variação percentual anual (APC) $=$ -34,7 (IC95\%: -50,3; -14,2) (Figura 4).

Das taxas em declínio, a categoria de cadáver encontrado liderou com variação negativa no estado $(56,3 \%)$, município $(78,1 \%)$ e na área integrada de segurança pública $(83,7 \%)$, ou seja, essa categoria, dentre todas as analisadas, apresentou a maior queda, em termos de VR\%, nas três localidades (Tabela 1).

Conforme a Tabela 1, as taxas de óbito enquadradas na categoria latrocínio, lesão corporal e policial morto em serviço, foram baixas, se confrontadas com outras categorias, tanto no estado e município do Rio de Janeiro, quanto na AISP 16 , em todo o período. A mediana das taxas de latrocínio foi maior na AISP 16, onde também observa-se maior variação, oscilando entre 0,6 e 3,8 latrocínios por 100.000 habitantes. 
Tabela 1. continuação

\begin{tabular}{|c|c|c|c|c|c|c|c|c|c|c|c|c|c|}
\hline \multirow{3}{*}{ Categoria } & \multicolumn{12}{|c|}{ Ano/Região } & \multirow{3}{*}{ VR\% } \\
\hline & \multicolumn{2}{|c|}{2008} & \multicolumn{2}{|c|}{2009} & \multicolumn{2}{|c|}{2010} & \multicolumn{2}{|c|}{2011} & \multicolumn{2}{|c|}{2012} & \multicolumn{2}{|c|}{2013} & \\
\hline & $\mathbf{n}$ & taxa & $\mathbf{n}$ & taxa & $\mathbf{n}$ & taxa & $\mathbf{n}$ & taxa & $\mathbf{n}$ & taxa & $\mathbf{n}$ & taxa & \\
\hline \multirow{8}{*}{$\begin{array}{l}\text { Homicídio Doloso } \\
\text { Auto de Resistência } \\
\text { Latrocínio } \\
\text { Cadáver Encontrado } \\
\text { Pessoa Desaparecida } \\
\text { Lesão Corporal } \\
\text { Policial Morto }\end{array}$} & \multicolumn{13}{|c|}{ Estado do Rio de Janeiro } \\
\hline & 5701 & 35,9 & 5794 & 36,2 & 4767 & 29,8 & 4279 & 26,6 & 4081 & 25,1 & 3885 & 29,1 & $-17,6$ \\
\hline & 1134 & 7,1 & 1053 & 6,6 & 855 & 5,3 & 523 & 3,2 & 419 & 2,6 & 341 & 2,5 & $-46,1$ \\
\hline & 234 & 1,5 & 221 & 1,4 & 156 & 1,0 & 118 & 0,7 & 142 & 0,9 & 117 & 0,9 & $-13,8$ \\
\hline & 609 & 3,8 & 495 & 3,1 & 545 & 3,4 & 519 & 3,2 & 538 & 3,3 & 426 & 3,2 & $-56,2$ \\
\hline & 5073 & 32,0 & 5425 & 33,9 & 5473 & 34,2 & 5488 & 34,1 & 5975 & 36,8 & 5067 & 36,7 & 41,9 \\
\hline & 44 & 0,3 & 44 & 0,3 & 43 & 0,3 & 44 & 0,3 & 25 & 0,2 & 32 & 0,2 & $-30,7$ \\
\hline & 25 & 0,2 & 31 & 0,2 & 23 & 0,1 & 13 & 0,1 & 16 & 0,1 & 18 & 0,1 & $-39,1$ \\
\hline \multirow{8}{*}{$\begin{array}{l}\text { Homicídio Doloso } \\
\text { Auto de Resistência } \\
\text { Latrocínio } \\
\text { Cadáver Encontrado } \\
\text { Pessoa Desaparecida } \\
\text { Lesão Corporal } \\
\text { Policial Morto }\end{array}$} & \multicolumn{13}{|c|}{ Município do Rio de Janeiro } \\
\hline & 2079 & 33,7 & 2155 & 34,8 & 1628 & 25,8 & 1417 & 22,3 & 1206 & 18,9 & 1100 & 20,6 & $-38,7$ \\
\hline & 688 & 11,2 & 643 & 10,4 & 485 & 7,7 & 283 & 4,5 & 283 & 4,4 & 181 & 3,5 & $-56,9$ \\
\hline & 98 & 1,6 & 90 & 1,5 & 68 & 1,1 & 62 & 1,0 & 53 & 0,8 & 40 & 0,8 & $-36,7$ \\
\hline & 256 & 4,2 & 192 & 3,1 & 192 & 3,0 & 159 & 2,5 & 150 & 2,3 & 115 & 2,1 & $-78,1$ \\
\hline & 2050 & 33,3 & 2268 & 36,7 & 2350 & 37,2 & 2121 & 33,4 & 2496 & 39,1 & 2107 & 38,6 & 43,6 \\
\hline & 22 & 0,4 & 14 & 0,2 & 22 & 0,3 & 24 & 0,4 & 15 & 0,2 & 18 & 0,4 & $-33,2$ \\
\hline & 17 & 0,3 & 26 & 0,4 & 15 & 0,2 & 9 & 0,1 & 9 & 0,1 & 10 & 0,2 & $-43,6$ \\
\hline & \multicolumn{12}{|c|}{ Ârea Integrada de Segurança Pública 16} & \\
\hline cídio Dolose & 128 & 26,9 & 144 & 30,0 & 98 & 20,3 & 65 & 13,2 & 84 & 17,1 & 63 & 17,9 & $-31,0$ \\
\hline Auto de Resist & 117 & 24,6 & 59 & 12,3 & 55 & 11,4 & 12 & 2,4 & 14 & 2,9 & 8 & 3,1 & $-54,1$ \\
\hline & 6 & 1,3 & 9 & 1,9 & 8 & 1,7 & 3 & 0,6 & 3 & 0,6 & 3 & 0,9 & $-32,2$ \\
\hline Cadaver Encol & 14 & 2,9 & 4 & 0,8 & 7 & 1,4 & 5 & 1,0 & 7 & 1,4 & 8 & 1,7 & $-83,7$ \\
\hline & 95 & 20,0 & 130 & 27,1 & 183 & 37,8 & 149 & 30,2 & 168 & 34,2 & 164 & 42,9 & 178,4 \\
\hline $\begin{array}{l}\text { Lesa } \\
\text { Poli }\end{array}$ & 2 & 0,4 & 1 & 0,2 & 1 & 0,2 & 1 & 0,2 & - & - & 2 & 0,4 & $-59,3$ \\
\hline roller & 2 & 0,4 & 1 & 0,2 & 1 & 0,2 & - & - & 3 & 0,6 & 1 & 0,4 & 103,5 \\
\hline
\end{tabular}

Fonte: Elaboração própria a partir de dados do Instituto de Segurança Pública, 2014. IBGE, 2013.

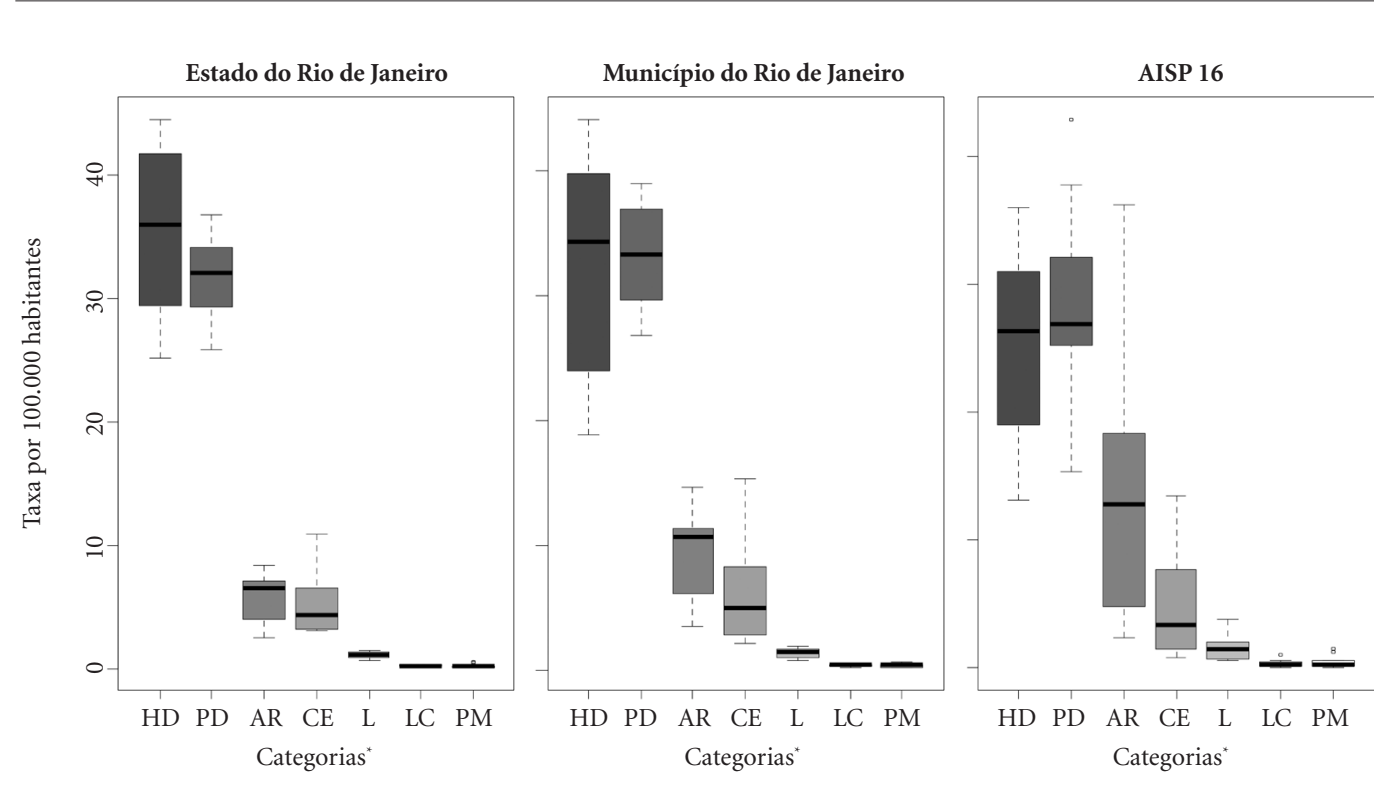

*Homicídio Doloso (HD); Pessoa Desaparecida (PD); Auto de Resistência (AR); Cadáver Encontrado (CE); Latrocínio (L); Lesão Corporal (LC); Policial Morto (PM). AISP 16: Área Integrada de Segurança Pública 16

Figura 2. Distribuição das taxas segundo categorias para estado, município e AISP 16. Rio de Janeiro, 2002-2013.

Fonte: Elaboração própria a partir de dados da Instituto de Segurança Pública, 2014. IBGE, 2013. 
Estado do Rio de Janeiro

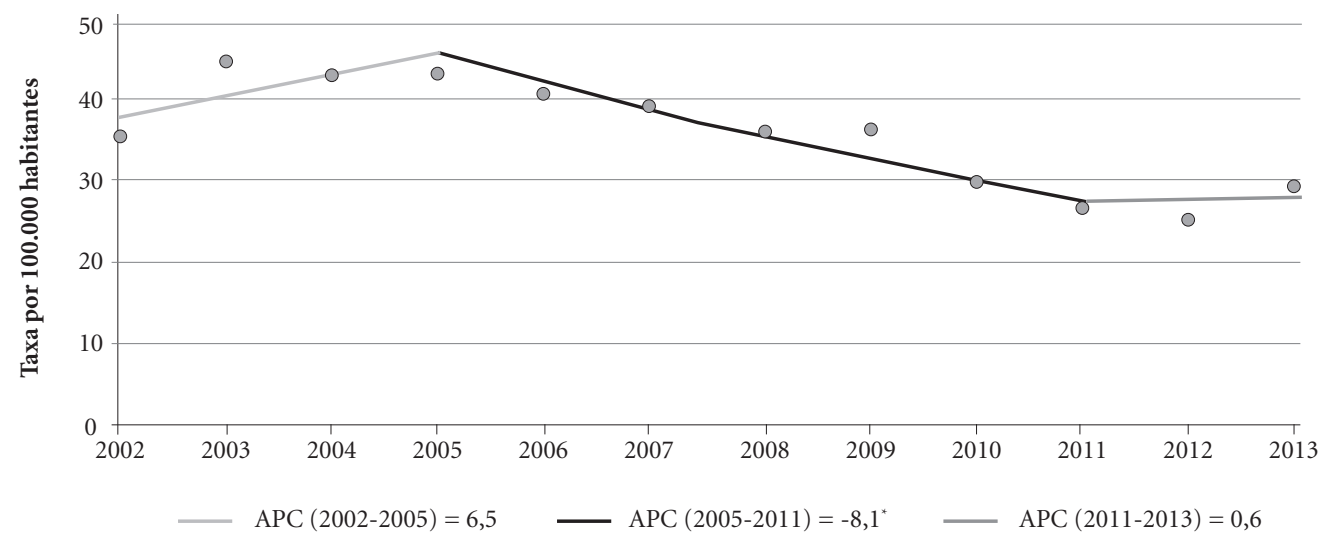

Município do Rio de Janeiro

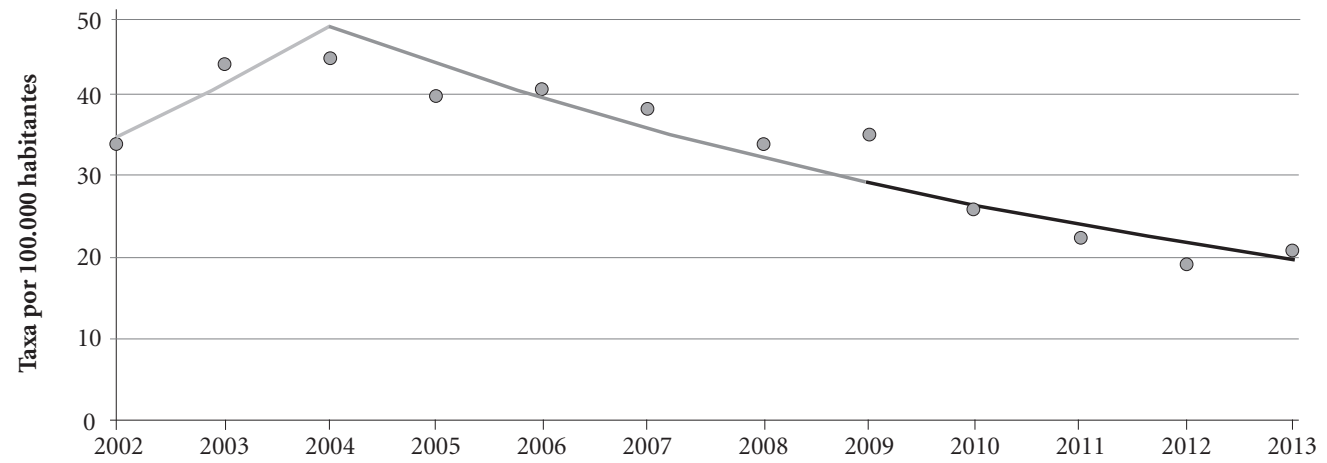

- APC $(2002-2004)=13,5-\operatorname{APC}(2005-2009)=-6,8 \quad \operatorname{APC}(2009-2013)=-13,0^{*}$

AISP 16

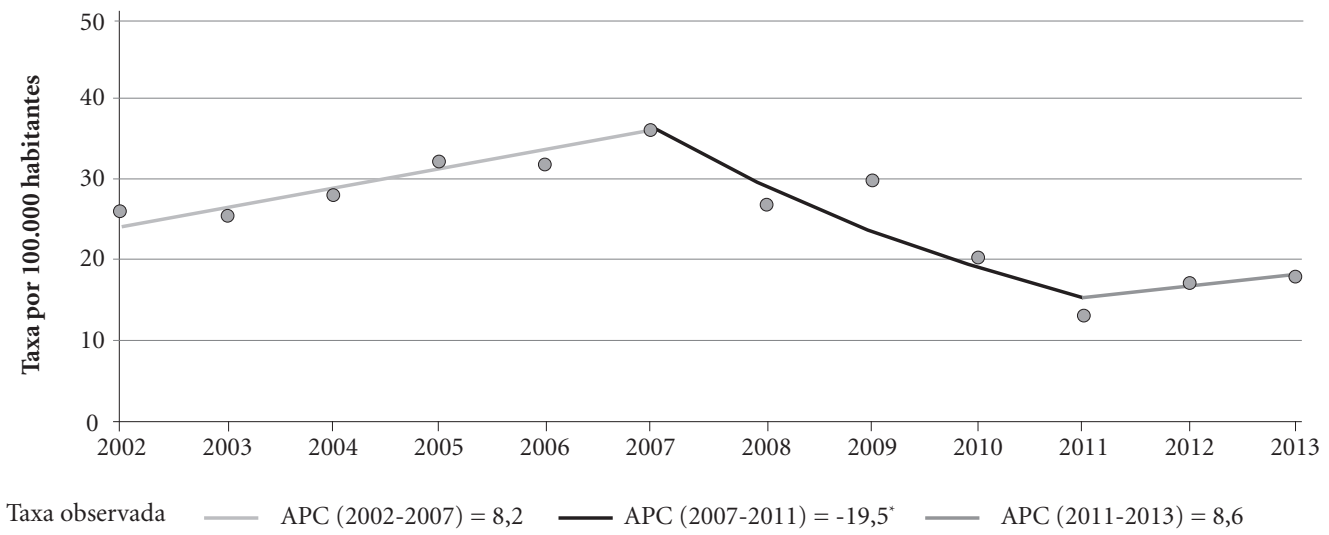

Figura 3. Variação percentual anual (APC) nas taxas de mortalidade por homicídio doloso, segundo área geográfica para estado, município e AISP 16. Rio de Janeiro, 2002-2013.

Fonte: Elaboração própria a partir de dados da Instituto de Segurança Pública, 2014. IBGE, 2013. 
Estado do Rio de Janeiro

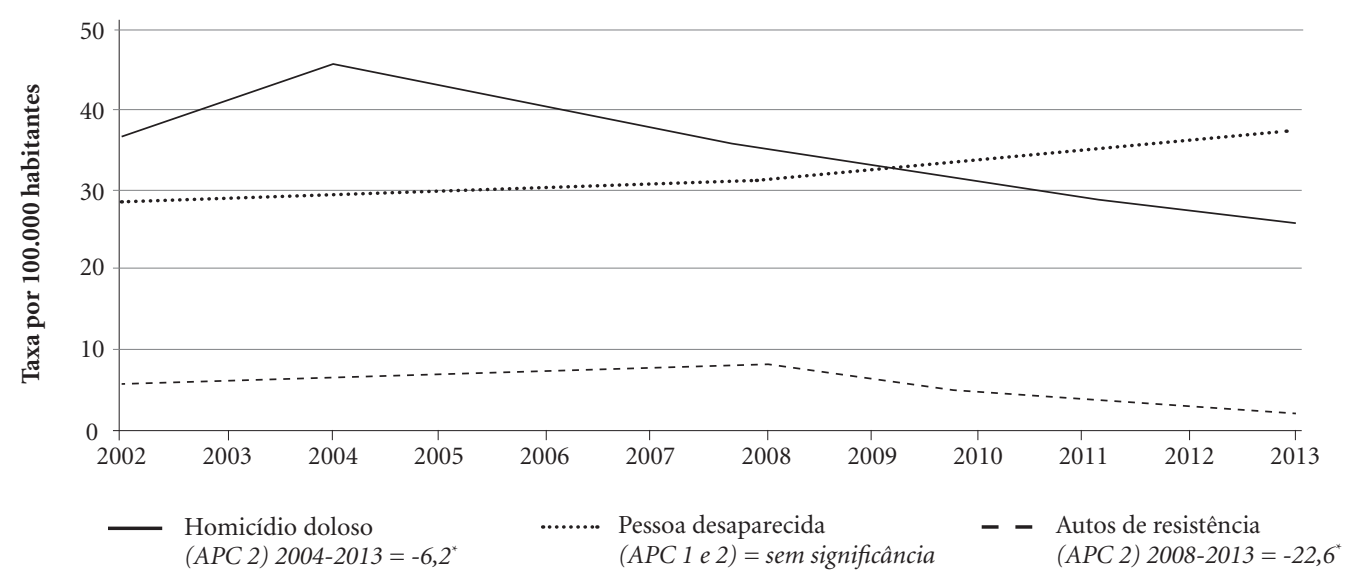

Município do Rio de Janeiro
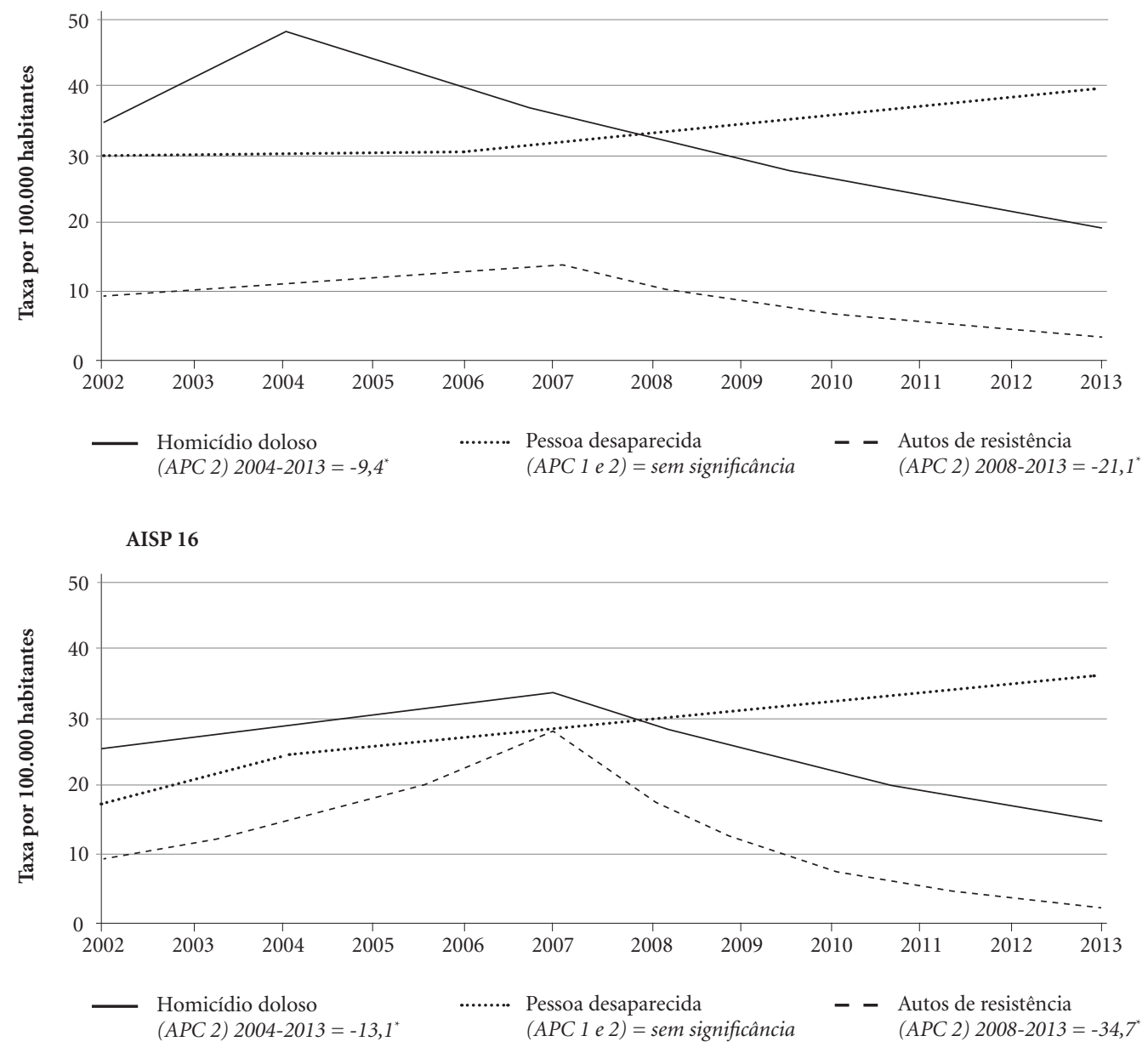

* $\mathrm{p}<0,05$. AISP 16: Área Integrada de Segurança Pública 16.

Figura 4. Distribuição das taxas (modeladas) de homicídio doloso, autos de resistência e pessoa desaparecida, com variação percentual anual (APC) estatisticamente significativa, nas três áreas geográficas. Rio de Janeiro, 2002-2013.

Fonte: Elaboração própria a partir de dados do ISP, 2014. IBGE, 2013. 
Merecem importante atenção os valores atípios (outliers) encontrados na categoria policiais mortos em serviço e lesão corporal seguida de morte na AISP 16 (Figura 2). A taxa de policiais mortos além de apresentar valores extremos em 2003 e 2007, teve um crescimento de $103,5 \%$ na área integrada de segurança pública, enquanto que no estado e município houve redução durante o período (Tabela 1). Lesão corporal seguida de morte cresceu mais na AISP 16 e teve maior variabilidade de taxas.

\section{Discussão}

Como foi visto, o homicídio doloso apresenta um padrão declinante. As taxas regrediram: $17,6 \%$ no Estado, 38,6\% na cidade e $31,0 \%$ na AISP 16, no período analisado. A redução observada nos registros de homicídios dolosos tem sido analisada por alguns pesquisadores como possível resultado do impacto de algumas medidas pontuais de enfrentamento do crime no Estado, como a implantação do Sistema Integrado de Metas (SIM) no Estado ${ }^{10}$, e a implantação das Unidades de Polícia Pacificadora (UPP) em algumas localidades na cidade do Rio de Janeiro ${ }^{11}$. Tais iniciativas não podem ser consideradas projetos totalmente estanques, já que as UPP, embora se concentrem no município do Rio de Janeiro, integram um projeto do Estado do Rio de Janeiro (assim como o SIM) e provavelmente têm impacto nos dados de violência e criminalidade registrados no Estado ${ }^{11}$.

O SIM consiste num programa criado pela Secretaria de Segurança do Estado do Rio de Janeiro, em 2009, para redução de alguns indicadores de violência, incluindo homicídios dolosos. O programa estabeleceu como meta a redução dos crimes classificados segundo o seu impacto na sensação de insegurança da população, como a letalidade violenta (somatório do número de vítimas de homicídios dolosos, lesões corporais seguida de morte, latrocínio e auto de resistência), o roubo de veículos e o de rua (somatório de incidências de roubo a transeunte, roubo em coletivo e roubo de aparelho celular), que compõem os indicadores estratégicos de criminalidade (IEC) utilizados. O SIM concede premiações às regiões e áreas integradas de segurança (RISP/ AISP), bem como aos agentes de segurança pública que alcançam as suas metas e obtêm os melhores resultados no controle da criminalidade ${ }^{8}$.

Já as UPP integram um projeto da secretaria estadual de segurança pública do Estado do Rio de Janeiro, criado em 2008, com o objetivo de “instituir polícias comunitárias em favelas como meio de recuperar territórios ocupados por grupos criminosos nessas localidades e pacificar as áreas". O policiamento comunitário consistiu na principal estratégia deste programa e segundo informações veiculadas no site upprj.com, o governo do Rio está investindo R\$ 15 milhões na qualificação da Academia de Polícia para que, até 2016, sejam formados cerca de 60 mil policiais no Estado ${ }^{1}$. Cabe ressaltar que apesar de o projeto estar vinculado ao governo do estado, e das áreas de maior violência letal do estado se concentrarem nos municípios da Baixada Fluminense, as UPP até agora implantadas situam-se apenas na cidade do Rio de Janeiro.

Dito isto, os achados deste trabalho sinalizam o início de uma queda mais acentuada nos homicídios dolosos no município do Rio, a partir do ano de 2009 até 2013, ainda que já houvesse uma diminuição no estado e no município desde 2005, sugerindo que as políticas citadas podem ter dito um impacto significativo para o declínio dos índices de homicídio, sobretudo no estado e na cidade do Rio de Janeiro ${ }^{8}$.

Na região da AISP16, os homicídios também tiveram uma redução nas taxas durante o período estudado. Porém, isso foi percebido mais nitidamente entre os anos 2007 e 2011. Com a instalação de UPP em 2012 nos dois grandes Complexos de favela da região, da Penha e do Alemão, ocupados pelas Forças de Pacificação do Exército desde 2010, nota-se uma estabilização entre as taxas nos anos de 2011 a 2013, com um leve aumento, não significativo. No entanto, como a implantação da UPP é recente nesta localidade, não é possível confirmar com precisão se há uma tendência de estabilidade ou ligeiro aumento no padrão dos homicídios.

A criação do SIM pode ter colaborado para a redução da letalidade violenta nas três unidades analisadas. Por outro lado, houve um aumento expressivo nas taxas de pessoas desaparecidas, tanto no município e no estado do Rio de Janeiro, quanto na região da AISP 16. Nessa última localidade, a categoria pessoa desaparecida apresentou tendência de crescimento desde 2004. As hipóteses para o crescimento do número de pessoas desaparecidas têm sido relacionadas ao aumento dos registros, devido à maior presença da polícia nos territórios com UPP; à mudança no padrão criminal ${ }^{11}$; à subnotificação dos dados de homicídios pela polícia ${ }^{10,12}$ e aos homicídios praticados por policiais, os chamados autos de resistência ${ }^{10}$. O que se observa, no presente trabalho, a partir da análise dos resultados é a exis- 
tência de espelhamento nas curvas correspondentes às taxas de pessoas desaparecidas, por um lado, e às taxas de homicídios dolosos e autos de resistência, por outro. Em outras palavras, a medida em que a taxa de homicídios dolosos e de autos de resistencia diminui, observa-se um incremento na de pessoas desaparecidas. Com relação aos autos de resistência, houve forte queda de suas taxas nas três localidades analisadas, principalmente na AISP 16. Segundo estudo de Borges et al. ${ }^{11}$, a respeito das UPPs no Rio de Janeiro em 2012, essa redução pode estar relacionada à diminuição das operações policiais violentas nas áreas pacificadas, como é o caso da AISP 16.

A AISP 16 engloba grandes Complexos de favelas, o que corrobora com os estudos que associam uma maior letalidade da ação policial nessas áreas ${ }^{4,13}$. Com relação a isto, pesquisa etnográfica realizada no Complexo de favelas do Alemão apontou que o ano de 2007 foi referido por diversos moradores como um ano bastante violento em função de execuções sumárias praticadas durante uma megaoperação policial que ficou conhecida como "chacina do Alemão". Esse achado corrobora e coincide com o pico da taxa de autos de resistência encontrado no presente trabalho ${ }^{14}$.

O relatório de um representante da Organização das Nações Unidas sobre este episódio, citado em uma pesquisa sobre execuções sumárias, arbitrárias ou extrajudiciais ${ }^{15}$ revela que o Chefe da Polícia Civil na época, ao ser questionado quanto às investigações dos homicídios perpetrados por policiais, afirmou que todos os mortos tinham antecedentes criminais, inclusive um menino de quatorze anos que levou quatro tiros nas costas ${ }^{15}$. Segundo a pesquisa ${ }^{15}$, as dificuldades para comprovar as execuções e permitir uma investigação dos fatos, fomentaram a recomendação da ONU ao Brasil de que abolisse a classificação "autos de resistência", já que esta consistiria em um "cheque em branco às mortes por policiais".

Existem muitas incertezas e desconfianças em torno da categoria "desaparecidos". Essas incertezas ecoam acusações de que os dados de pessoas desaparecidas "na verdade" encobririam um elevado número de homicídios e autos de resistência em algumas localidades. A motivação para este encobrimento seria a necessidade de se atingir as metas do SIM no que se refere à redução de Indicadores Estratégicos de Criminalidade, sobretudo os que estão relacionados à letalidade. Isso tem sido observado em debates com a presença de movimentos sociais e ensaios acadêmicos que denunciam a intensificação da violência policial em áreas de UPPS. No entanto, esta violência não estaria representada oficialmente, devido à suposta camuflagem de dados pelos agentes de ponta ${ }^{10}$.

Uma análise precisa sobre o elevado número de desaparecidos demandaria uma investigação detalhada sobre o perfil dessas pessoas, evidenciando ou não a associação entre os perfis de homicídios, autos de resistência e pessoas desaparecidas. Outro problema com este tipo de inferência é a visão reducionista de que o policial de ponta é o único responsável pelo sucesso ou fracasso de uma política de segurança pública.

Sem ignorar a persistência de abusos de poder e os vários episódisos de violência policial é necessário ter em conta que nas áreas de UPP houve, de fato, a diminução dos confrontos entre grupos criminosos e entre estes e a polícia, sobretudo nos anos iniciais de instalação das unidades. Fatos percebidos também durante trabalho de campo etnográfico e nos depoimentos recolhidos com moradores da área. Mais recentemente, embora os confrontos tenham retornado à rotina dos moradores de algumas favelas pacificadas, pode ser dito que as mortes no período não se comparam aos anteriores à instalação das UPPs. No entanto, segundo as análises ${ }^{11,16}$, se não houver maiores investimentos na segurança pública, pode haver um recrudescimento do quadro de violência letal.

Assim como outros estudos já demonstraram a relação desigual entre autos de resistência e policiais mortos, o presente trabalho corrobora com estas análises, já que foi possível observar os homicídios cometidos por policiais na cidade do Rio de Janeiro. Em 2007 foram mortos 17 policiais em serviço e 688 pessoas por "autos de resistência", ou seja, para cada policial morto, 40,4 civis morreram, como também foi constatado em pesquisa sobre a evolução dos homicídios ${ }^{17}$.

Como foi visto, a taxa de policiais mortos apresentou valores extremos em 2003 e 2007, representando 6 e 7 policiais mortos, respectivamente. Em todo o período analisado teve um crescimento na AISP16, enquanto que estado e município conseguiram reduzir a taxa. Todavia, o aumento verificado na região da AISP16 pode ser relativizado dado que em número absoluto essa taxa representa dois policiais mortos no ano de 2012, a qual pode ser considerada desproporcional se comparada ao número de civis mortos por autos de resistência (14 casos), como já comentado. Apesar disso, vários estudos indicam que os policiais, independente do território onde atuam, consideram a existência do risco em sua 
profissão ${ }^{18}$. Nessa linha, há estudos que reiteram que a percepção de risco é maior que a vitimização, o que não significa ignorar a vulnerabilidade da categoria a sofrer agravos em sua saúde mental e física ${ }^{19}$.

A violência, por ser um fenômeno complexo e multicausal evidencia a necessidade de uma atuação interdisciplinar, multiprofissional e intersetorial, que atue de modo a prevenir e reduzir os índices alarmantes de morbimortalidade ${ }^{20}$. Desse modo, analisar as iniciativas promovidas pelo setor da segurança pública que impactem na saúde e na qualidade de vida da população pode estreitar os vínculos entre o campo da saúde e o da segurança pública. Nesse sentido, é necessário desenvolver abordagens colaborativas que favoreçam a comunicação entre esses setores e o fortalecimento de redes intersetoriais de prevenção da violência ${ }^{21}$.

\section{Conclusões}

A análise e a interconexão dos achados deste estudo com a saúde coletiva foi o grande desafio aqui proposto. No entanto, existem limitações relacionadas ao próprio desenho de estudo e à restrição de informações das bases de segurança pública. Um dos entraves é a falta de detalhamento acerca das categorias utilizadas, como idade, sexo e raça. Outro ponto refere-se à impossibilidade de linkage de sistemas de informação ou de bases de dados secundários que tratam da violência no Brasil.

Contudo, os resultados apontam não apenas para o padrão de evolução de taxas e declínio de homicídio, mas, sobretudo, para a importância e a possibilidade de se debater a temática da violência, relacionada à saúde e à segurança pública, em uma perspectiva complexa e intersetorial. Complexa, por observar e contemplar diferentes aspectos, como a implantação das UPP e do SIM, as incógnitas ligadas aos desaparecidos e o entroncamento da violência com a saúde. E intersetorial, por levar em consideração múltiplos setores, como a saúde, a segurança e o planejamento de políticas públicas.

A interface entre as perspectivas socioantropológica e da saúde pública permitiu contemplar aspectos subjetivos e objetivos ligados aos homicídios já que a magnitude deste fenômeno impacta fortemente a saúde pública, não só pelo número de vítimas diretas, mas também por agravos mentais e emocionais de familiares e amigos próximos as vítimas; diminuindo a qualidade de vida das pessoas e das coletividades.

Outras investigações poderão avaliar o impacto das UPP na redução no número de homicídios, através de um estudo mais amplo, contemplando os dados e os pontos aqui abordados, além de pesquisa de campo, entrevistas com a população e estudos de casos individuais e comparados entre as áreas que tenham UPP e as que não têm. Além dessas constatações, a pesquisa poderá ser complementada a partir de comparações com outras AISP no estado e na cidade, principalmente as da zona sul; áreas nas quais verifica-se que os homicídios apresentam menores números ${ }^{10}$.

O enfrentamento deste quadro exige o desenvolvimento de um conjunto de ações articuladas e sistematizadas entre diferentes setores governamentais, de diversificados segmentos sociais e da população em geral, já preconizado, desde 2001, pela Política Nacional de Redução da Morbimortalidade por Acidentes e Violência ${ }^{22}$.

Nesse sentido, pretendeu-se com este trabalho fomentar o diálogo entre a saúde e a segurança pública, para que se possa contribuir para a ampliação da discussão sobre a magnitude dos homicídios no Brasil.

\section{Colaboradores}

FLM Gadelha Cardoso contribuiu na concepção e redação do artigo, resultados e discussão. FR Cecchetto e JS Corrêa contribuíram na redação do artigo, resultados e discussão. TO Souza contribuiu na metodologia e discussão dos resultados. Todos os autores contribuíram para redação final do artigo. 


\section{Referências}

1. Waiselfisz JJ. Mapa da violência 2013: mortes matadas por armas de fogo. Brasília: Cebela; 2013.

2. Zaluar A. Integração Perversa: pobreza e tráfico de drogas. Rio de Janeiro: Editora FGV; 2004.

3. Souza ER, Lima MLC. Panorama da violência urbana no Brasil e suas capitais. Cien Saude Colet 2006; 11(Supl.):1211-1222.

4. Zaluar A, Barcellos C. Mortes prematuras e conflito armado pelo domínio das favelas no Rio de Janeiro. Rev. bras. Ci. Soc. 2013; 28(81):17-31.

5. Barcellos C, Zaluar A. Homicídios e disputas territoriais nas favelas do Rio de Janeiro. Rev Saude Publica 2014; 48(1):94-102.

6. R Core Team. R: A language and environment for statistical computing. Vienna: R Foundation for Statistical Computing; 2014.

7. Kim HJ, Fay MP, Feuer EJ, Midthune DN. Permutation tests for joinpoint regression with applications to cancer rates. Stat Med 2000; 19(3):335-351.

8. Rio de Janeiro. Instituto de Segurança Pública. [acessado 2014 dez 1]. Disponível em: http://www.isp.rj.gov. $\mathrm{br} /$ Conteudo.asp?ident $=38$

9. Machado da Silva LA, organizador. Vida sob cerco: violência e rotina nas favelas do Rio de Janeiro. Rio de Janeiro: Faperi, Nova Fronteira; 2008.

10. Misse DG. Cinco anos de UPP: Um breve balanço. DILEMAS: Revista de Estudos de Conflito e Controle Social 2014; 7(3):675-700.

11. Borges D, Ribeiro E, Cano I, organizadores. Os donos do morro: uma avaliação exploratória do impacto das unidades de polícia pacificadora (UPPs) no Rio de Janeiro. Rio de Janeiro: Fórum Brasileiro de Segurança Pública - LAV-UERJ; 2012.

12. Cano I, coordenador. "No sapatinho": a evolução das milícias no Rio de Janeiro (2008-2011). Rio de Janeiro: Fundação Heinrich Böll; 2012.

13. Ramos S. Meninos do Rio: Jovens, violência armada e polícia nas favelas cariocas. Boletim Segurança e Cidadania 2009; 13:1-28.

14. Correa JS. As representações de jovens moradores do Complexo do Alemão no Rio de Janeiro sobre a implantação das Unidades de Polícia Pacificadora - UPP - 2013 [dissertação]. Rio de Janeiro: Fundação Oswaldo Cruz; 2013.
15. Leão IV. Execuções sumárias, arbitrárias ou extrajudiciais: Efetividades das recomendações da ONU no Brasil [dissertação]. São Paulo: USP; 2011.

16. Machado da Silva LA. Afinal, qual é a das UPPs? [acessado 2014 nov 1]. Disponível em: http://www.observatoriodasmetropoles.ufrj.br/artigo_machado_UPPs.pdf

17. Misse M. Autos de Resistência: Uma análise dos homicídios cometidos por policiais na cidade do Rio de Janeiro (2001-2011). In: Misse M, coordenador. Núcleo de Estudos da Cidadania, Conflito e Violência Urbana. Rio de Janeiro: Universidade Federal do Rio de Janeiro; 2011. (Relatório Final). p. 20-37.

18. Constantino P, Ribeiro AP, Correia, BSC. Percepção do risco entre policiais civis de diferentes territórios do Estado do Rio de Janeiro. Cien Saude Colet 2013; 18(3):645-655.

19. Constantino P. Riscos vividos e percebidos pelos Policiais Civis de Campos dos Goytacazes [tese]. Rio de Janeiro: Fundação Oswaldo Cruz; 2006.

20. Minayo MCS. Violência e Saúde. Rio de Janeiro: Editora Fiocruz; 2006

21. World Health Organization (WHO). Preventing Violence. A guide to implementing the recommendations of the World report on violence and health. Geneva: WHO; 2004.

22. Brasil. Ministério da Saúde (MS). Secretaria de Vigilância em Saúde. Política nacional de redução da morbimortalidade por acidentes e violências: Situação de Saúde. 2a ed. Brasília: Editora do Ministério da Saúde; 2005.

Artigo apresentado em 04/03/2015

Aprovado em 13/08/2015

Versão final apresentada em 15/08/2015 